\title{
The vitamin and mineral content of fruits and vegetables grown in Israel
}

\author{
BY S. HALEVY, HANNAH KOTH AND K. GUGGENHEIM \\ Laboratory of Nutrition, Department of Biochemistry, Hebrew University- \\ Hadassah Medical School, ferusalem, Israel \\ (Received I I April 1957)
}

Many countries of the world have serious problems in feeding their people, and Israel is no exception. In developing a sound programme for the food and nutrition of any country information on the composition of its home-grown foods is of particular importance.

The chemical composition and nutritive value of foods produced in Palestine have been investigated by Kovacs, Guggenheim \& Kligler (1939) and Guggenheim \& Bichowsky (1948), but their reports are incomplete. We present here a report on the analysis of over 300 samples of fifty-four fruits and vegetables collected in Jerusalem between November 1954 and September 1956. The nutrients determined were carotene, thiamine, riboflavin, nicotinic acid, ascorbic acid, calcium, iron, sodium and potassium. Calcium and iron are the only two minerals for which specified dietary allowances are recommended and in which human diets are often deficient ((U.S.A.) National Research Council, I953), but the importance of sodium and potassium in therapeutic diets has recently been recognized ((U.S.A.) National Research Council, I952, I954).

Fruits and vegetables furnish considerable amounts of nutrients to the Israeli diet. During 1949-54, from 207 to $237 \mathrm{~kg} /$ head were consumed yearly (Lvavi, 1955). Among the vegetables, tomatoes come first, constituting from 23 to $29 \%$ of the annual vegetable consumption. Cucumbers ( $11-14 \%$ ) come next and then carrots $(6-10 \%)$ and cabbage (6-8\%). These figures compare favourably with those for other countries in the Near East. According to the Second World Food Survey (Food and Agriculture Organization of the United Nations, 1952) the annual supply of fruits and vegetables per head in $1946-9$ was $124 \mathrm{~kg}$ in Egypt, $108 \mathrm{~kg}$ in Iran, 10o $\mathrm{kg}$ in Iraq, $207 \mathrm{~kg}$ in Syria and $185 \mathrm{~kg}$ in Turkey.

\section{METHODS}

Samples. All samples were purchased in the open market in Jerusalem. They represent fruits and vegetables as bought by the ordinary consumer. No information as to the genetic history of the fruits and vegetables could be obtained. Most of them are, however, not truly native, but were imported during the last 60 years from Europe or the United States. Whenever possible, the samples were analysed a few hours after purchase. Some samples were stored for from $\mathrm{I}$ to 3 days at $2^{\circ}$ before analysis. 
Ascorbic acid, however, was always determined on the day of purchase. Vitamins and minerals were examined in the edible portion only.

A Waring Blendor was used to prepare the slurry, and suitable fractions were taken for analysis.

Vitamins. For extraction and assay of vitamins, the procedures outlined by the Association of Vitamin Chemists (195I) were followed. More specifically, carotene was separated by the solvent-partition method (Association of Vitamin Chemists, $195 \mathrm{I}$, p. 63) or chromatographically (Association of Vitamin Chemists, I95 I, p. 52), depending on the nature of the sample. Determination of thiamine was done by the thiochrome method (Association of Vitamin Chemists, I95I, p. III); riboflavin fluorimetrically (Association of Vitamin Chemists, 195 I, p. I66); nicotinic acid microbiologically (Association of Vitamin Chemists, I95 I, p. I80) and ascorbic acid titrimetrically with 2:6-dichlorophenolindophenol (Association of Vitamin Chemists, I 95 I , p. 76) after extraction with $2 \%$ oxalic acid. Deeply coloured fruits and vegetables were extracted with dichlorophenolindophenol-xylene (Association of Vitamin Chemists, I95 I, p. 87); the extracts were assayed for ascorbic acid by means of a Klett colorimeter.

Minerals. For examination of calcium and iron representative samples weighing from 5 to $r o g$ were ashed in porcelain crucibles for several hours at $55^{\circ}$. Calcium was determined by the oxalate method (Association of Official Agricultural Chemists, I950, p. I95) and iron with the orthophenanthroline reagent (Association of Official Agricultural Chemists, I950, p. 194). Samples destined for analysis for sodium and potassium were ashed in the same way and the ash was then dissolved in nitric acid; suitable dilutions were made up with twice-distilled water. Sodium and potassium were determined with a flame photometer (Barclays Instruments). Repeated examinations of the twice-distilled water proved it to be almost free from sodium and potassium ions.

\section{RESULTS}

The results are presented in Table $\mathbf{I}$. The figures for each item are the means of from five to eight analyses of individual samples. Some figures from a previous publication, which has appeared in a local Government Report (Guggenheim \& Bichowsky, 1948), have been added to the results obtained by us. They are marked with an asterisk. Results from an earlier report (Kovacs et al. 1939) have not been included, since the methods then used for extraction and determination of vitamins are now open to criticism.

\section{DISCUSSION}

The richest sources of carotene appeared to be beet leaves, carrots, parsley, pepper, pumpkin and spinach. Relatively high values for thiamine were found in broad beans, maize and peas; for riboflavin in mushrooms, okra, green onions and parsley; for nicotinic acid in broad beans, celery leaves, guava, maize, mushrooms, parsley and peas; and for ascorbic acid in cabbage, cauliflower, guava, parsley, pepper, strawberry and citrus fruits. Some of our figures exceed markedly those given in the Food 


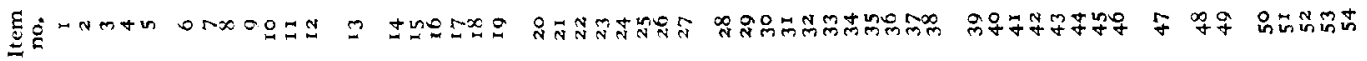
穴

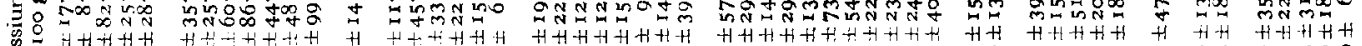

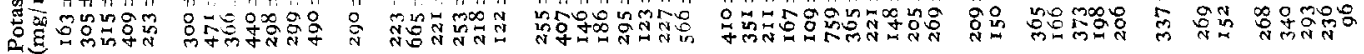

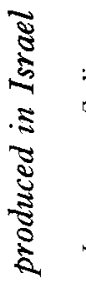

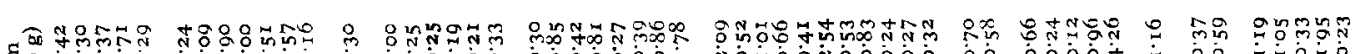

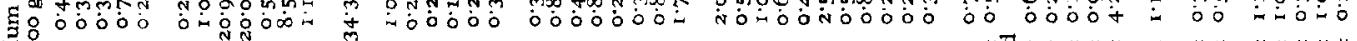

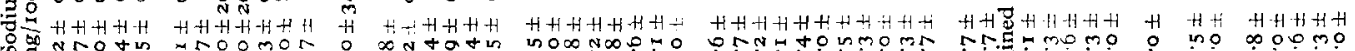

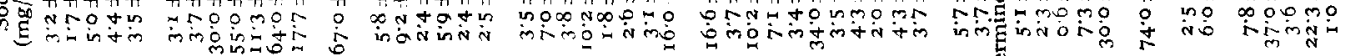

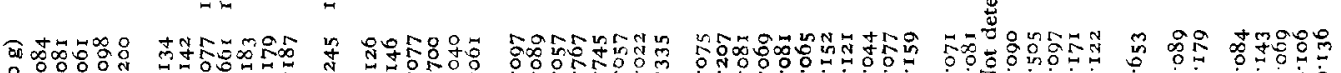

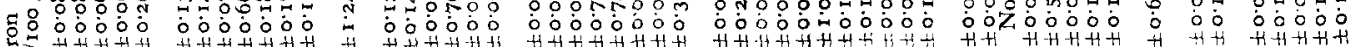
然

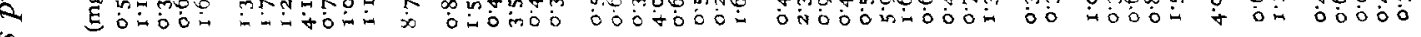

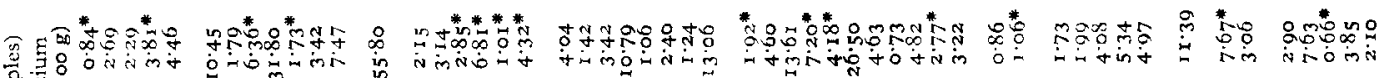

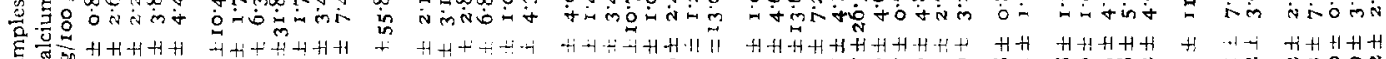

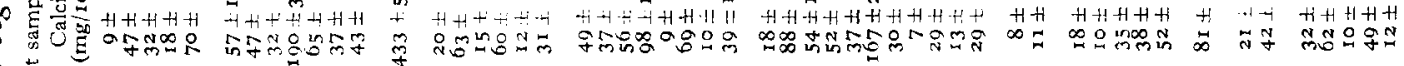
节

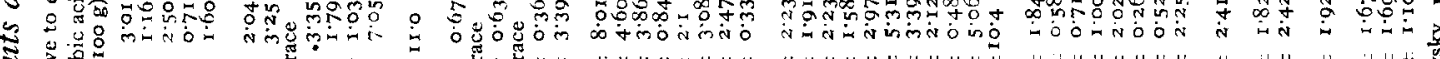

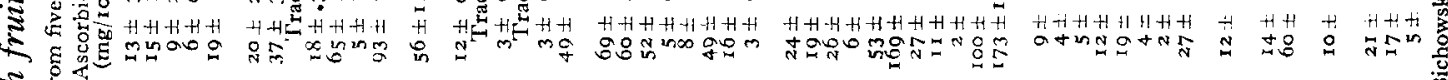

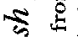

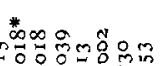

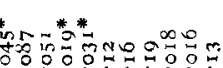

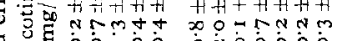

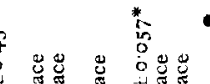

ב⿱

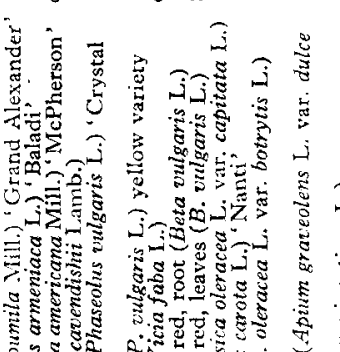

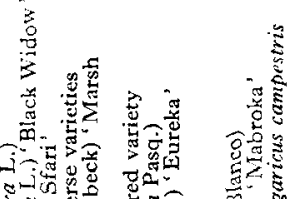

mint

等

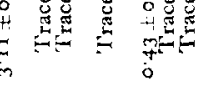

है

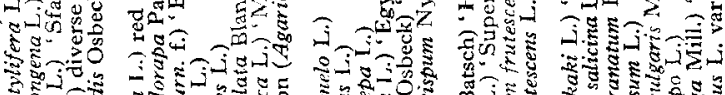

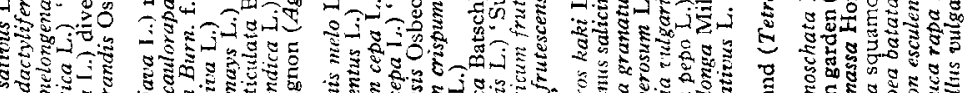
ñ

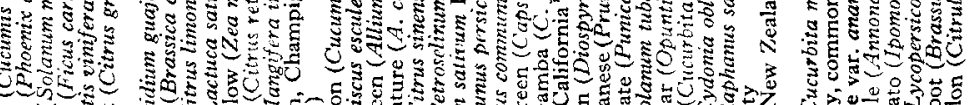

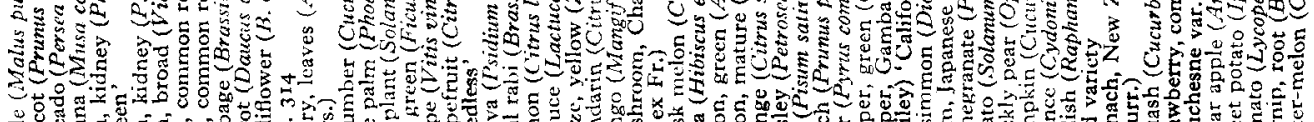

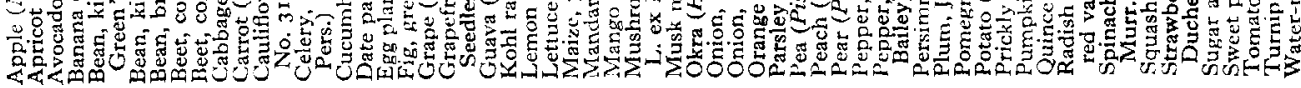

盖宫 
Composition Tables issued by FAO (Chatfield, 1954) for international use, which is a compilation from a great number of values scattered throughout the literature; such differences were shown by beet leaves, green pepper, and pumpkin for carotene, avocado for thiamine, dates and okra for riboflavin, lettuce for nicotinic acid, and apricots for ascorbic acid.

The best sources of calcium proved to be celery, beet leaves and parsley. Good sources were green beans, cabbage, dates, figs, lettuce, mandarins, okra, spinach and sweet potatoes. High values for iron were found in beet and celery leaves, figs, lettuce, okra, parsley and spinach.

Sodium-restricted diets have increased in importance in recent years because of their therapeutic value in congestive heart failure, cirrhosis of the liver, hypertensive disease, certain diseases of the kidneys and the toxaemias of pregnancy. Generally, fruits and vegetables are poor sources of sodium ((U.S.A.) National Research Council, I954). Most of our results agree with those taken from the literature and given in Table I of the (U.S.A.) National Research Council's (1954) publication. It should, however, be borne in mind that several fruits and vegetables, such as beet, root as well as leaves, carrots, celery leaves and spinach, are somewhat rich in sodium.

The occurrence of a state of potassium depletion, which is frequently encountered after trauma and haemorrhage, in diabetic acidosis and in severe diarrhoea, has recently been stressed ((U.S.A.) National Research Council, 1952). For many of those conditions, consumption of fruit juices, known for their high potassium content, is recommended. Our results show that some fruits and vegetables, among them avocado, banana, broad beans, beet leaves, cauliflower, dates, kohlrabi, mushrooms, musk melons and parsley, are good sources of potassium and may be used with advantage in potassium-repletion diets.

\section{SUMMARY}

I. More than 300 samples of fifty-four kinds of fruits and vegetables, grown in Israel, were analysed for carotene, thiamine, riboflavin, nicotinic acid, ascorbic acid, calcium, iron, sodium and potassium. The values per $100 \mathrm{~g}$ of the fresh edible portion are tabulated.

2. Some nutritional aspects of the results are discussed.

We are indebted to Dr D. V. Zaitschek, Department of Pharmacognosy, Hebrew University, for his help in identifying the fruits and vegetables and to Mr Y. Fattal for his technical help.

The flame-photometric determinations of sodium and potassium were carried out in the Laboratory for Clinical Research of the Hadassah-University Hospital.

This study was supported in part by a grant from the Ministry of Health of the State of Israel. 
REFERENCES

Association of Official Agricultural Chemists (1950). Official and Tentative Methods of Analysis, 7 th ed. Washington, D.C.: Association of Official Agricultural Chemists.

Association of Vitamin Chemists (1951). Methods of Vitamin Assay, and ed. New York: Interscience Publishers.

Chatfield, C. (1954), F.A.O. nutr. Stud. no. I I.

Food and Agriculture Organization of the United Nations (1952). Second World Food Survey. Rome: Food and Agriculture Organization of the United Nations.

Guggenheim, K. \& Bichowsky, L. (1948). Rep. Activ. Palest. Bd sci. industr. Res. 1945-8, p. 37.

Kovacs, A. S., Guggenheim, K. \& Kligler, I. J. (1939). The Composition of Vegetables, Fruits and Milk Produced in Palestine. Jerusalem: Hebrew University Press.

Lvavi, J. (1955). Food Balance Sheet of Israel (1949/50-1953/54). Jerusalem: Central Bureau of Statistics.

National Research Council: Food and Nutrition Board (1952). Publ. nat. Res, Coun., Wash., no. 234.

National Research Council: Food and Nutrition Board (1953). Publ. nat. Res. Coun., Wash., no. 302, revised.

National Research Council: Food and Nutrition Board (1954). Publ. nat. Res. Coun., Wash., no. 325.

\title{
The utilization of acetic, propionic and butyric acids by fattening sheep
}

\author{
By D. G. ARMSTRONG AND K. L. BLAXTER \\ Hannah Dairy Research Institute, Kirkhill, Ayr
}

(Received 29 April 1957)

Previous work showed that when steam-volatile fatty acids were given to fasting sheep as the sole source of energy, the heat increments of the acids expressed as Cal./ $100 \mathrm{Cal}$. metabolized were, acetic acid $4 \mathrm{I} \%$, propionic acid $13 \%$ and $n$-butyric acid $16 \%$ (Armstrong \& Blaxter, 1957). These measurements represent the inevitable loss of energy as heat which occurs when the acids are utilized instead of body fat and body protein, the two constituents oxidized by fasting animals to meet the energy demands of essential metabolic processes. It was shown subsequently (Armstrong, Blaxter \& Graham, 1957) that, although singly the acids showed marked differences in the efficiency with which they were utilized, when they were present in mixtures representing the fairly wide range of molar proportions of acids likely to be formed by the rumen micro-organisms which ferment dietary carbohydrate, they all exhibited closely similar heat increments of $\mathrm{I}_{4}-\mathrm{I}_{5} \mathrm{Cal} / \mathrm{r}$ (00 Cal. metabolized. This high efficiency of utilization appears to manifest itself after entry of the acids into the tricarboxylicacid cycle (Armstrong \& Blaxter, 1957).

Oxidation of the acids to provide the free energy necessary for the maintenance of minimal functional activity is not the sole way in which the acids could be utilized by the animal. Studies with acetic acid labelled with ${ }^{14} \mathrm{C}$ have shown that this acid is incorporated into many compounds. Lipogenesis in mammary tissue of the ruminant results in considerable incorporation of acetic acid into the constituent fatty acids of 